\title{
Comparing the Areas of Interest in the Field of Functional Gastrointestinal Disorder and Neurogastroenterology and Motility Between the East and the West
}

\author{
Ju Yup Lee, ${ }^{1,2}$ Nayoung Kim, ${ }^{1,3 *}$ Gwang Ha Kim, ${ }^{4}$ and Gi Hyun Kim ${ }^{1}$ \\ ${ }^{1}$ Department of Internal Medicine, Seoul National University Bundang Hospital, Seongnam, Korea; ${ }^{2}$ Department of Internal Medicine, Keimyung \\ University School of Medicine, Daegu, Korea; ${ }^{3}$ Department of Internal Medicine and Liver Research Institute, Seoul National University College \\ of Medicine, Seoul, Korea; and ${ }^{4}$ Department of Internal Medicine, Pusan National University School of Medicine; and Biomedical Research \\ Institute, Pusan National University Hospital, Busan, Korea
}

There is a paucity of studies that compare the differences in published articles submitted from the East and the West in the area of neurogastroenterology and motility (NM). To compare the article topics from the East and the West which have been published, 5 Western (Gastroenterology, Gut, American Journal of Gastroenterology, American Journal of Physiology-Gastrointestinal and Liver Physiology, and Neurogastroenterology and Motility) and 3 Eastern gastrointestinal journals (Journal of Gastroenterology, Journal of Gastroenterology and Hepatology, and Journal of Neurogastroenterology and Motility) were selected based on the impact factor. Published papers were classified into 12 categories and 60 subcategories. The titles and abstracts of review articles, original articles, and meta-analyses from these journals were reviewed for the last 2 years (2013-2014). In case of Journal of Neurogastroenterology and Motility which is published quarterly, this search was performed for 5 years (2010-2014). Of the total 2656 reviewed articles, 842 (260 from the East and 582 from the West) were classified into the category of NM. The most frequently published papers from the Western researchers were categorized as brain-gut interaction, visceral hypersensitivity, and irritable bowel syndrome, whereas those from the Eastern researchers were categorized as gastroesophageal reflux disease, functional dyspepsia, and irritable bowel syndrome. This difference between the East and the West is not just due to the journal itself, but it also depends on the author's affiliation and their ability to perform high quality research in the area of the NM. These data provide evidence for the research trend and give valuable information to the researchers for determining subjects for the study and for selecting proper journals for publishing their studies.

(J Neurogastroenterol Motil 2015;21:503-510)

Key Words

East; Journal; Motility; Neurogastroenterology; West

Received: April 9, 2015 Revised: June 22, 2015 Accepted: June 23, 2015

(c) This is an Open Access article distributed under the terms of the Creative Commons Attribution Non-Commercial License (http://creativecommons. org/licenses/by-nc/4.0) which permits unrestricted non-commercial use, distribution, and reproduction in any medium, provided the original work is properly cited.

*Correspondence: Nayoung Kim, MD, PhD

Department of Internal Medicine, Seoul National University Bundang Hospital, 82, Gumi-ro 173 beon-gil, Bundang-gu, Seongnam, Gyeonggi-do 13620, Korea

Tel: +82-31-787-7008, Fax: +82-31-787-4051, E-mail: nayoungkim49@empas.com

Financial support: None.

Conflicts of interest: None.

Author contributions: Ju Yup Lee analyzed and interpreted the data, and wrote a manuscript; Nayoung Kim designed, organized, and mediated the present study, and supervised the manuscript; Gwang Ha Kim advised design and supported preparing manuscript; and Gi Hyun Kim collected the data.

ORCID: Nayoung Kim, http://orcid.org/0000-0002-9397-0406; Ju Yup Lee, http://orcid.org/0000-0003-0021-5354. 


\section{Introduction}

The area of neurogastroenterology and motility (NM) includes studies of the brain, the gut, and their interactions that are associated with the understanding and management of gastrointestinal (GI) motility and the related functional GI disorders (FGIDs). FGID is defined as several variable combinations of chronic or recurrent GI symptoms with no definitely identified underlying pathophysiology. ${ }^{1}$ FGID is one of the most common medical conditions and its chronic symptoms markedly reduce the quality of life, ${ }^{2}$ and it reflects a variety of underlying pathophysiological abnormalities. ${ }^{3}$ The prevalence of functional dyspepsia (FD) and irritable bowel syndrome (IBS), which are representative forms of FGIDs, varies considerably among populations, and ethnicity, dietary factors, and socioeconomic conditions affect the variability. ${ }^{4-7}$ Therefore, the interest or methods for approaching these disorders may be different between Eastern and Western researchers.

Many researchers from the East and the West perform studies and publish many papers in the clinical and basic pathophysiological fields of NM. Thus, most GI journals regard the field of $\mathrm{NM}$ as one of the important subjects. Despite great interest in the field of NM, there is a paucity of studies regarding the difference in articles submitted from the East and the West in the area of NM. In this review, the article topics which have been published in the Eastern and the Western GI journals as well as those of authors from the East and the West in the field of NM were investigated.

\section{Journal Selection, Literature Search, and Categorization of Topics of Neurogastroenterology and Motility}

Five Western and 3 Eastern GI journals were selected based on the impact factor (IF). Five Western GI journals consisted of 3 major GI journals (Gastroenterology [GE]: the official journal of the American Gastroenterological Association [2013 IF = 13.926], Gut [GUT]: the official journal of the British Society of Gastroenterology [2013 IF = 13.319], and American Journal of Gastroenterology [AJG]: the official journal of the American College of Gastroenterology [2013 IF = 9.213]), 1 NM journal, Neurogastroenterology and Motility [NGM]: the official journal of the European Gastrointestinal Motility Society and American Neurogastroenterology and Motility Society [2013 IF
$=3.424]$ ), and 1 journal dealing with the basic physiology of the GI field, American Journal of Physiology-Gastrointestinal and Liver Physiology [AJP-GI]: the official journal of the American Physiological Society [2013 IF $=3.737$ ].

Three Eastern GI journals included 2 GI journals; Journal of Gastroenterology [JGE]: the official journal of the Japanese Society of Gastroenterology [2013 IF $=4.020]$ and Journal of Gastroenterology and Hepatology [JGH]: the official publication of the Asian Pacific Association of Gastroenterology and an affiliated publication of the Asian Pacific Association for the Study of the Liver, Gastroenterological Society of Australia, the Hong Kong Society of Gastroeterology, and the Thailand Gastroenterology Association [2013 IF = 3.627]), and $1 \mathrm{NM}$ journal (Journal of Neurogastroenterology and Motility [JNM]: a joint official journal of the Korean Society of Neurogastroenterology and Motility, the Thai Neurogastroenterology and Motility Society, the Japanese Society of Neurogastroenterology and Motility, the Indian Motility and Functional Disease Association, the Chinese Society of Gastrointestinal Motility, the South East Asia Gastro-Neuro Motility Association, the Taiwan Neurogastroenterology and Motility Society, and the Asian Neurogastroenterology and Motility Association (ANMA) [2013 IF = 2.698]).

Literature searches were performed via each journal's web site. Each article's title and abstract (full-text if needed) of the 8 selected journals were carefully reviewed by 17 GI fellows at Seoul National University Bundang Hospital. Among the review articles, original articles, and meta-analyses published from 2013 to 2014, those in the field of NM were included, while editorials and case reports were excluded. In case of JNM, a quarterly journal, the articles published during the recent 5 years (2010-2014) were analyzed.

Topics of NM were classified by prof. G.H.K into 12 categories with 60 subcategories as shown in Figure 1. Each article was classified into 60 subcategories and then re-classified into one of the 12 categories. In the next step, the article was grouped into the East and the West according to the corresponding author's country. "Eastern country" included Asian countries including the Middle East. The US, Europe, and Australia were grouped as "Western country," mainly based on culture and diet.

\section{Analysis of Publications According to the Corresponding Author's Country, the East and the West}

A total of 2656 articles were retrieved in our searches, of which, 842 articles (260 from the East and 582 from the West) 

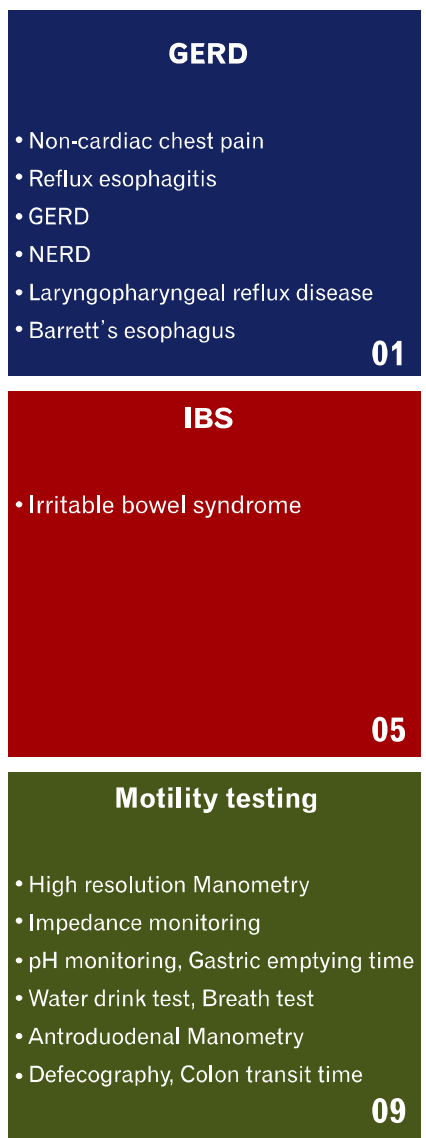

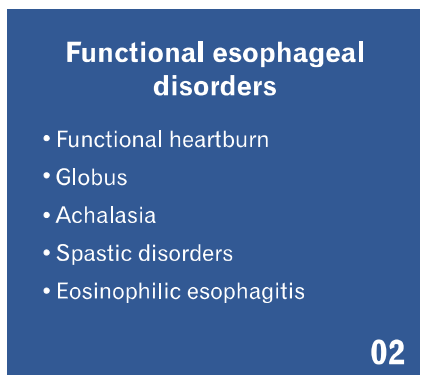

02
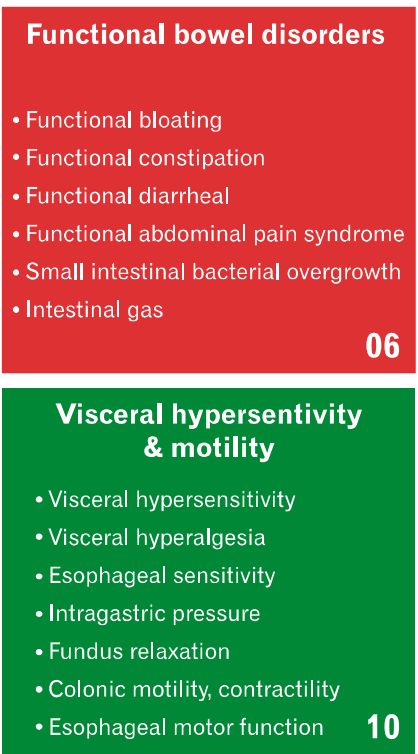
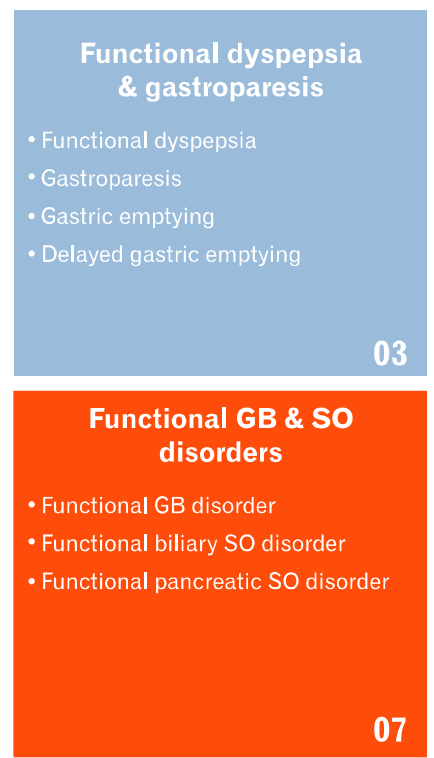

Brain gut interaction
/ENS/ICC

- Interstitial cell of Cajal

- Enteric nervous system

- Brain-gut interaction

- Brain-gut axis
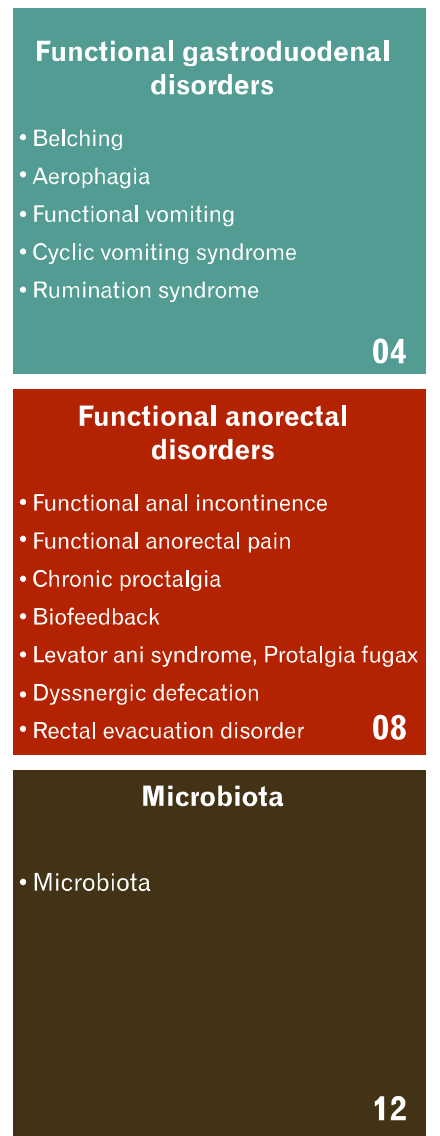

Figure 1. Twelve categories and 60 subcategories for the classification of neurogastroenterology and motility. GERD, gastroesophageal reflux disease; NERD, nonerosive reflux disease; IBS, irritable bowel syndrome; GB, gall bladder; SO, sphincter of Oddi; ENS, enteric nervous system; ICC, interstitial cell of Cajal.

Table 1. Number of Total Searched Articles and Articles on Neurogastroenterology and Motility in Each Journal

\begin{tabular}{llccccccccc}
\hline $\begin{array}{l}\text { Journal name } \\
\text { Total searched articles }\end{array}$ & & GE & GUT & AJG & NGM & AJP-GI & JGE & JGH & JNM \\
$(456)$ & $(346)$ & $(303)$ & $(330)$ & $\begin{array}{c}\text { Total } \\
(429)\end{array}$ & $\begin{array}{c}(293) \\
(399)\end{array}$ & $\begin{array}{c}(220) \\
(2656)\end{array}$ \\
\hline Articles in the area of NM & East (n) & 2 & 0 & 4 & 42 & 10 & 22 & 30 & 150 & 260 \\
& West (n) & 59 & 21 & 32 & 288 & 91 & 14 & 7 & 70 & 582 \\
& Total (n [\%]) & $61(13.4)$ & $21(6.1)$ & $36(11.9)$ & $330(100)$ & $101(23.5)$ & $36(12.3)$ & $37(9.3)$ & $220(100)$ & 842 \\
\hline
\end{tabular}

NM, neurogastroenterology and motility; GE, Gastroenterology; AJG, American Journal of Gastroenterology; NGM, Neurogastroenterology and Motility; AJP-GI, American Journal of Physiology-Gastrointestinal and Liver Physiology; JGE, Journal of Gastroenterology; JGH, Journal of Gastroenterology and Hepatology; JNM, Journal of Neurogastroenterology and Motility.

were found to be focused on NM. The proportion of articles on $\mathrm{NM}$ in the 8 selected journals during the search period was $13.4 \%$ in GE, $6.1 \%$ in GUT, $11.9 \%$ in $\mathrm{AJG}, 100 \%$ in NGM, $23.5 \%$ in AJP-GI, $12.3 \%$ in JGE, $9.3 \%$ in JGH, and $100 \%$ in JNM, respectively (Table 1). When the articles on NM were analyzed in terms of the corresponding author's country, the number of articles from the East and the West were 2 (3.3\%) and 59 (96.7\%), respectively in GE, 0 and 21 (100\%) in GUT, 4
$(11.1 \%)$ and $32(88.9 \%)$ in AJG, $42(12.7 \%)$ and $288(87.3 \%)$ in NGM, 10 (9.9\%) and 91 (90.1\%) in AJP-GI, 22 (61.1\%) and $14(38.9 \%)$ in JGE, $30(81.1 \%)$ and $7(18.9 \%)$ in JGH, and 150 (68.2\%) and 70 (31.8\%) in JNM (Fig. 2). The Eastern countries that published articles on NM in the 8 journals included Korea $(94,37 \%)$, Japan $(65,25 \%)$, China $(40,16 \%)$, Taiwan $(17,7 \%)$, India (16, 6\%), and others (Thailand, Iran, Malaysia, Hong Kong, Sri Lanka, Singapore, and Turkey) (Fig. 3). 


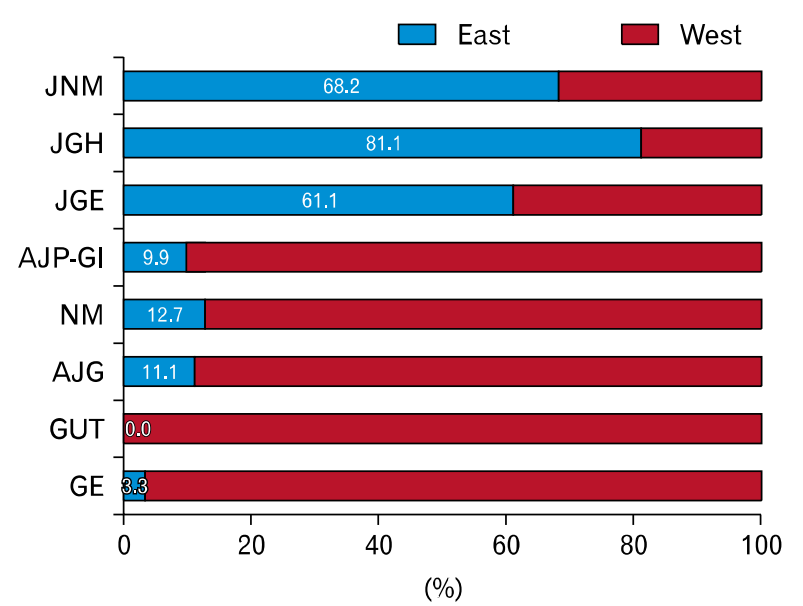

Figure 2. Proportion of Eastern and Western articles on neurogastroenterolog and motility in Eastern and Western gastrointestinal journals. Proportion of Eastern articles in JGH, JNM, and JGE is $81.1 \%, 68.2 \%$, and $61.1 \%$, respectively; however, proportion of Eastern articles in NGM, AJG, AJP-GI, GE, and GUT is $12.7 \%, 11.1 \%$, $9.9 \%, 3.3 \%$, and $0 \%$, respectively. JNM, Journal of Neurogastroenterology and Motility; JGH, Journal of Gastroenterology and Hepatology; JGE, Journal of Gastroenterology; AJP-GI, American Journal of PhysiologyGastrointestinal and Liver Physiology; NM, Neurogastroenterology and Motility; AJG, American Journal of Gastroenterology; GE, Gastroenterology.

\section{Differences in the Research Topics of Articles Depending on Corresponding Authors and Each Journal}

In the next step, we analyzed the main research topics from each journal and they were categorized depending on corresponding authors.

\section{Differences in the Research Topics of Articles by the Eastern and the Western Corresponding Authors}

The 5 research topics for the Eastern corresponding authors were gastroesophageal reflux disease (GERD; 58, 22.3\%), FD $(49,18.8 \%)$, IBS $(40,15.4 \%)$, motility test $(26,10.0 \%)$, and visceral hypersensitivity $(24,9.2 \%)$. On the other hand, the 5 main research topics for the Western corresponding authors were brain-gut interaction $(107,18.4 \%)$, visceral hypersensitivity $(105,18.0 \%)$, IBS $(94,16.2 \%)$, FD $(64,11.0 \%)$, and GERD $(59,10.1 \%)$ (Fig. 4).

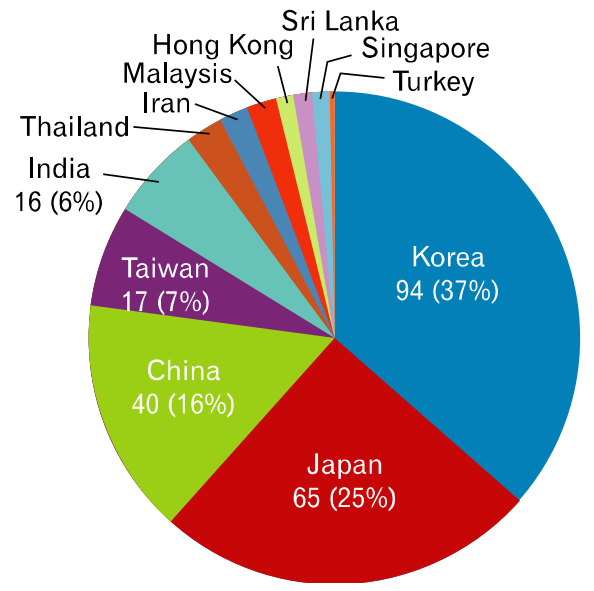

Figure 3. Proportion of Eastern articles on NM in 8 gastrointestinal journals. The Eastern countries that published articles on neurogastroenterology and motility in the 8 journals are Korea $(94,37 \%)$, Japan $(65,25 \%)$, China $(40,16 \%)$, Taiwan $(17,7 \%)$, India $(16,6 \%)$, and others (Thailand, Iran, Malaysia, Hong Kong, Sri Lanka, Singapore, and Turkey).

\section{The Research Topics of Five Gastrointestinal Journals}

In GE, a total of 61 articles on NM were published in 2013-2014; 36 were from the US, 5 from the UK, from Germany, 2 from China and 2 from Iran. Main research fields of interest were IBS (26.2\%), brain-gut interaction (21.3\%), functional esophageal disorders (16.4\%), GERD (13.1\%), and visceral hypersensitivity (9.8\%). In GUT, a total of 21 articles on NM were published in 2013-2014; 8 were from Belgium, 3 from the US, and 3 from the UK. The major research topics were categorized as brain-gut interaction (28.6\%), IBS (23.8\%), and visceral hypersensitivity (23.8\%). In AJG, a total of 36 articles on NM were published in 2013-2014; 17 articles were from the US, 3 from Australia, 2 from China, and 2 from Japan. Main research topics were categorized as IBS (55.6\%), FD (16.7\%) and functional bowel disorders (13.9\%).

In JGE, a total of 36 articles on NM were published in 2013-2014; 18 were from Japan, 5 from the US, and 3 from Spain. Main research topics were categorized as GERD (19.4\%), FD (13.9\%), functional esophageal disorders (13.9\%), brain-gut interaction $(13.9 \%)$, and visceral hypersensitivity (11.1\%). In JGH, a total of 37 articles on NM were published in 2013-2014; 7 articles were from China, Korea, and Australia each. Main research topics were categorized as GERD (45.9\%), FD (13.5\%), IBS (10.8\%), and motility test (10.8\%) (Table 2). 


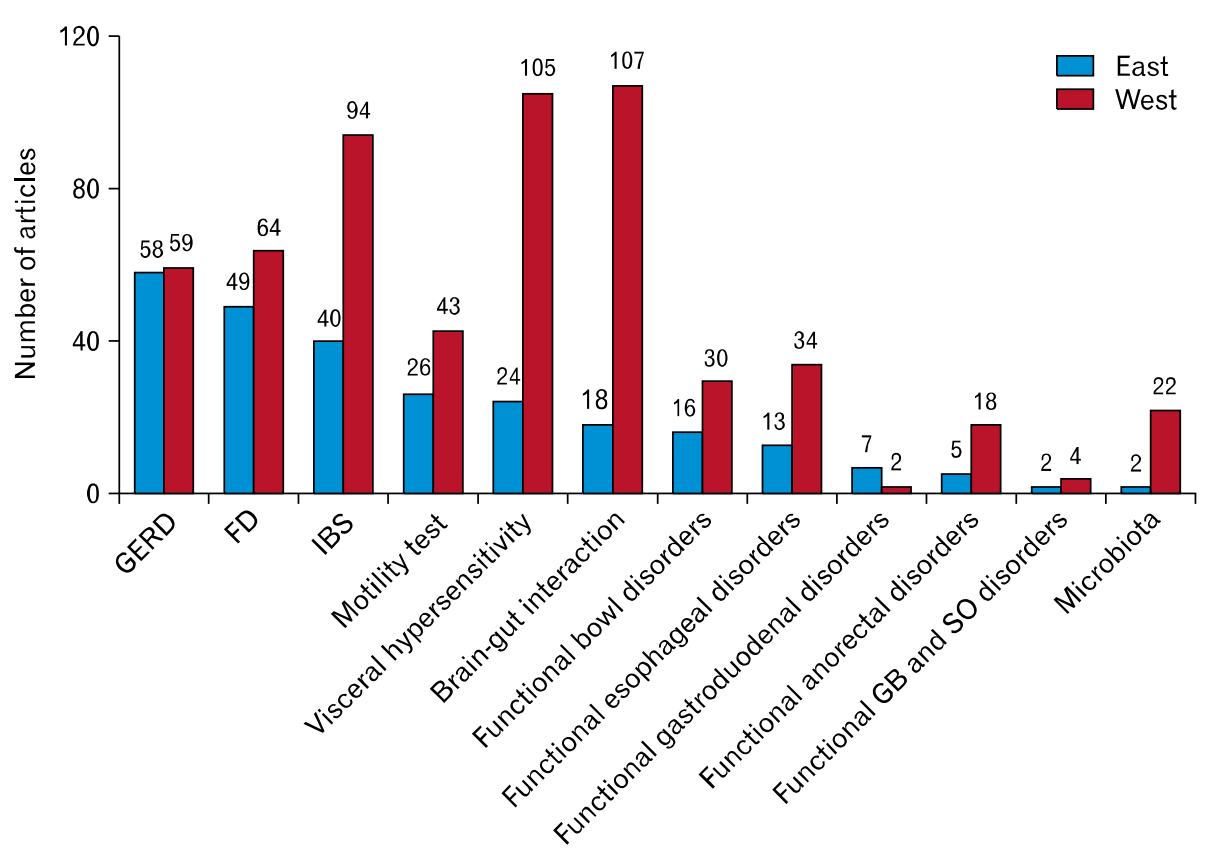

Figure 4. Research field of interest of Eastern researchers versus Western researchers. The order of research field of interest of Eastern researchers is gastroesophageal reflux disease (GERD; $58,22.3 \%$ ), functional dyspepsia (FD; $49,18.8 \%)$, and irritable bowel syndrome (IBS; 40, 15.4\%), whereas the order of research field of interest of Western researchers is brain-gut interaction $(107,18.4 \%)$, visceral hypersensitivity $(105,18.0 \%)$, and IBS (94, $16.2 \%)$. GB, gall bladder; $\mathrm{SO}$, sphincter Oddi.

\section{The Research Topics of Basic Research Journal}

In AJP-GI, a total of 101 articles on NM were published in 2013-2014. Most of the articles were from the US (55, 54.5\%), while 5 were from China, 5 from Japan, and 1 from Korea. Main research topics were categorized as visceral hypersensitivity $(32.7 \%)$ and brain-gut interaction $(20.8 \%)$ (Table 2).

\section{Comparison of Research Topics Between 2 Neurogastroenterology and Motility Journals}

In NGM, a total of 330 articles on NM were published in 2013-2014. Large number of articles were from the US (96, 29.1\%), while 15 were from China, 13 from Japan, and 7 were from Korea. Main research topics were categorized as brain-gut interaction (20.9\%), visceral hypersensitivity (18.5\%), and FD (13.6\%). In JNM, a total 220 articles on NM were published from 2010-2014; 79 were from Korea, 38 from the US, 21 from Japan, and 12 from India. Main research topics were categorized as IBS (21.8\%), GERD (20.9\%), and FD (18.2\%) (Table 2).

\section{Possible Causes of the Differences in Research Topics in the Field of Neurogastroenterology and Motility Between the East and the West -}

Many sociocultural factors, such as gender, age, economic state, education level, food, race, stress, or climate and drugs, af- fect the expression and course of FGIDs. ${ }^{3,8}$ It is likely that the research topic could be related to the disease prevalence. The pooled prevalence of IBS is $11.2 \%$ (95\% confidence interval [CI], 9.8-12.8) in Northern Europe, 15.0\% (95\% CI, 11.0-20.0) in Southern Europe, $11.8 \%$ (95\% CI, 7.4-17.2) in North America, and $14.0 \%$ (95\% CI, 13.0-15.0) in Australia. ${ }^{5}$ However, the prevalence of IBS is relatively low in many Asian studies (< $10.0 \%),{ }^{5,8}$ although Chang et $\mathrm{al}^{8}$ recently reported that the current prevalence of IBS in Asia is similar to that of the Western countries. These differences may force Western researchers to pay more attention to prevalent diseases such IBS. In addition, Western researchers tend to perform basic researches such as brain-gut interaction and visceral hypersensitivity in the field of NM compared to Eastern researchers. The differences in ways of thinking between the East and West may also affect the research fields.

In contrast, GERD and FD are the areas of great interest in the East. ${ }^{9}$ GERD has a higher prevalence in the West than in the East. ${ }^{10}$ Several factors such as differences in ethnicity and the prevalence of obesity are associated with the prevalence of GERD. ${ }^{9}$ Recent population-based studies showed that the prevalence of GERD has been increasing in Eastern Asia. ${ }^{11-14}$ The increase of GERD prevalence in Asia seems to be associated with epidemiological changes such as rapid economic growth, changes in eating habits, decreasing prevalence of Helicobacter pylori, and the growing number of obese people. ${ }^{9,15}$ We expected the prevalence of GERD to increase continuously similar to that in the 
Table 2. Distribution of the Corresponding Author's Country and the Research Field for Articles on Neurogastroenterology and Motility in Each Journal

\begin{tabular}{|c|c|c|c|c|}
\hline $\begin{array}{c}\text { Journal } \\
\text { (Number of articles on NM) }\end{array}$ & Country & $\mathrm{n}(\%)$ & Area of Interest & $\mathrm{n}(\%)$ \\
\hline \multirow{5}{*}{$\begin{array}{l}\text { Gastroenterology } \\
(\mathrm{n}=61)\end{array}$} & US & $36(59.0)$ & Irritable bowel syndrome & $16(26.2)$ \\
\hline & UK & $5(8.2)$ & Barin-gut interaction & $13(21.3)$ \\
\hline & Germany & $4(6.6)$ & Functional esophageal disorders & $10(16.4)$ \\
\hline & China & $1(1.6)$ & Gastroesophageal reflux disease & $8(13.1)$ \\
\hline & Iran & $1(1.6)$ & Visceral hypersensitivity & $6(9.8)$ \\
\hline \multirow{5}{*}{$\begin{array}{l}\text { Gut } \\
\qquad(\mathrm{n}=21)\end{array}$} & Belgium & $8(38.1)$ & Barin-gut interaction & $6(28.6)$ \\
\hline & US & $3(14.3)$ & Irritable bowel syndrome & $5(23.8)$ \\
\hline & UK & $3(14.3)$ & Visceral hypersensitivity & $5(23.8)$ \\
\hline & Spain & $2(9.5)$ & Functional bowl disorders & $2(9.5)$ \\
\hline & Italy & $1(4.8)$ & Functional esophageal disorders & $1(4.8)$ \\
\hline \multirow{4}{*}{$\begin{array}{l}\text { American Journal of Gastroenterology } \\
(\mathrm{n}=36)\end{array}$} & US & $17(47.2)$ & Irritable bowel syndrome & $20(55.6)$ \\
\hline & UK & $2(5.6)$ & Functional bowel disorders & $5(13.9)$ \\
\hline & Japan & $2(5.6)$ & Visceral hypersensitivity & $3(8.3)$ \\
\hline & China & $2(5.6)$ & Functional anorectal disorder & $1(2.8)$ \\
\hline \multirow{5}{*}{$\begin{array}{l}\text { American Journal of Physiology-Gastrointestinal and } \\
\text { Liver Physiology }(\mathrm{n}=101)\end{array}$} & US & $55(54.5)$ & Visceral hypersensitivity & $33(32.7)$ \\
\hline & Canada & $7(6.9)$ & Barin-gut interaction & $21(20.8)$ \\
\hline & China & $5(5.0)$ & Gastroesophageal reflux disease & $11(10.9)$ \\
\hline & Japan & $5(5.0)$ & Functional dyspepsia & $10(9.9)$ \\
\hline & Korea & $1(0.1)$ & Microbiota & $10(9.9)$ \\
\hline \multirow{5}{*}{$\begin{array}{l}\text { Journal of Gastroenterology } \\
\qquad(\mathrm{n}=36)\end{array}$} & Japan & $18(50.0)$ & Gastroesophageal reflux disease & $7(19.4)$ \\
\hline & US & $5(13.9)$ & Functional dyspepsia & $5(13.9)$ \\
\hline & Spain & $3(8.3)$ & Functional esophageal disorders & $5(13.9)$ \\
\hline & China & $2(5.6)$ & Barin-gut interaction & $5(13.9)$ \\
\hline & Korea & $1(2.8)$ & Visceral hypersensitivity & $4(11.1)$ \\
\hline \multirow{3}{*}{$\begin{array}{l}\text { Journal of Gastroenterology and Hepatology } \\
\qquad(\mathrm{n}=37)\end{array}$} & Australia & $7(18.9)$ & Irritable bowel syndrome & $4(10.8)$ \\
\hline & Japan & $6(16.2)$ & Motility test & $4(10.8)$ \\
\hline & Taiwan & $5(13.5)$ & Functional esophageal disorders & $3(8.1)$ \\
\hline \multirow{5}{*}{$\begin{array}{l}\text { Neurogastroenterology and Motility } \\
(\mathrm{n}=330)\end{array}$} & US & $96(29.1)$ & Barin-gut interaction & $69(20.9)$ \\
\hline & UK & $26(7.9)$ & Visceral hypersensitivity & $61(18.5)$ \\
\hline & China & $15(4.5)$ & Functional dyspepsia & $45(13.6)$ \\
\hline & Japan & $13(3.9)$ & Motility test & $37(11.2)$ \\
\hline & Korea & $7(2.1)$ & Irritable bowel syndrome & $33(10.0)$ \\
\hline \multirow{5}{*}{$\begin{array}{l}\text { Journal of Neurogastroenterology and Motility } \\
(\mathrm{n}=220)\end{array}$} & Korea & $79(35.9)$ & Irritable bowel syndrome & $48(21.8)$ \\
\hline & US & $38(17.3)$ & Gastroesophageal reflux disease & $46(20.9)$ \\
\hline & Japan & $21(9.5)$ & Functional dyspepsia & $40(18.2)$ \\
\hline & India & $12(5.5)$ & Motility test & $18(8.2)$ \\
\hline & Taiwan & $9(4.1)$ & Visceral hypersensitivity & $16(7.3)$ \\
\hline
\end{tabular}

NM, neurogastroenterology and motility.

West, but there is a report that the prevalence of erosive esophagitis is not significantly increased in a healthy Korean population since 2006 till date. ${ }^{16}$ Thus, there must be another ethnic factor which might explain the difference between the West and the
East. Extraesophageal reflux symptoms and non-erosive reflux disease are more frequent in the East than in the West. ${ }^{17-21}$ In addition, the response rate to a proton pump inhibitor is lower in the East than in the West. ${ }^{22-25}$ This kind of interest in the Eastern 
countries might explain why GERD is the main research topic in Asia.

Another cause of the difference in the research area of NM between the East and the West was that the proportion of basic research articles was higher in Western journals. For example, basic research articles, such as animal or cell studies, accounted for $27.9 \%$ of the studies in GE and for $23.8 \%$ of the studies in GUT versus $19.4 \%$ of the studies in JGE. The proportion of basic research articles in NGM was $38.8 \%$, which was higher than that of JNM (29.1\%). Since studies about pathophysiological mechanism of FGIDs usually require significant experience, team approach, and adequate funding compared to general clinical studies; it is very difficult to publish a good paper in a high impact journal. This could be one of the reasons why studies about visceral hypersensitivity and brain-gut interaction have been published more often in Western journal with high IF. Many researchers from Eastern countries have difficulty in performing basic pathophysiological studies because of few experts in this field, less fund, technical limitations, clinical overburden on medical doctors, and so on. Due to these reasons, Eastern researcher tends to concentrate on clinical studies such as those on GERD, FD, and IBS, which requires relatively less time until publication than basic research. Long history and popularity of Western journals are another reasons for this difference, considering the short history of JNM. In spite of a comprehensive review of more than 2500 articles using well-established categories, a 2-year review might not clearly discern the differences between the East and the West.

\section{The Role of Journal of Neurogastroenterology and Motility}

JNM has played an important role in the publication of the Eastern articles on NM so far. The main aim of JNM is to provide world researchers with a technique of publishing their research results in the field of NM. Prior to JNM, NGM was the only international journal in this field. One of the most distinguished characteristics of JNM is that it has become a common official journal of many Asian societies. Therefore, JNM has become available to a very large global pool of researches and readers, especially in Asia. ${ }^{26}$ In the future, the topics of JNM will change if more Western researchers submit their studies to JNM and the ability of Asian countries to perform research increases. This could happen in the near future.

\section{Conclusion}

Even though our analysis for differences in research topics between the East and the West in journals related to the field of NM is limited to the last 2 years, the fields of interest in Eastern GI journals were GERD and FD, whereas those in Western journals were brain-gut interaction and visceral hypersensitivity. A few Eastern studies were found to be published in the Western GI journals with high IF, and Eastern GI journals included many articles from Eastern countries. From the analysis of the recent publication trend in the field of NM in 8 major GI journals, we were able to obtain valuable information about the differences in the research field interest between the Eastern and the Western researchers as well as between journals. The difference in interest between the Eastern and the Western journals is not just due to the journal itself, but it also depends on the author's affiliation and their background which enables them to perform high quality research in the area of the pathophysiology of NM. These data provide evidence for the research trend and give valuable information to the researchers for determining subjects for the study and for selecting proper journals for publishing their studies.

\section{References}

1. Corazziari E. Definition and epidemiology of functional gastrointestinal disorders. Best Pract Res Clin Gastroenterol 2004;18: 613-631.

2. Lacy BE, Weiser KT, Kennedy AT, Crowell MD, Talley NJ. Functional dyspepsia: the economic impact to patients. Aliment Pharmacol Ther 2013;38:170-177.

3. Chang L, Toner BB, Fukudo S, et al. Gender, age, society, culture, and the patient's perspective in the functional gastrointestinal disorders. Gastroenterology 2006;130:1435-1446.

4. Mahadeva S, Goh KL. Epidemiology of functional dyspepsia: a global perspective. World J Gastroenterol 2006;12:2661-2666.

5. Lovell RM, Ford AC. Global prevalence of and risk factors for irritable bowel syndrome: a meta-analysis. Clin Gastroenterol Hepatol 2012;10:712-721, e4.

6. Kang JY. Systematic review: the influence of geography and ethnicity in irritable bowel syndrome. Aliment Pharmacol Ther 2005;21: 663-676.

7. Miwa H, Watari J, Fukui H, et al. Current understanding of pathogenesis of functional dyspepsia. J Gastroenterol Hepatol 2011; 26(suppl 3):53-60.

8. Chang FY, Lu CL, Chen TS. The current prevalence of irritable bowel syndrome in Asia. J Neurogastroenterol Motil 2010;16:389400.

9. Jung HK. Epidemiology of gastroesophageal reflux disease in Asia: a systematic review. J Neurogastroenterol Motil 2011;17:14-27. 
10. Hongo M, Nagasaki Y, Shoji T. Epidemiology of esophageal cancer: orient to occident. Effects of chronology, geography and ethnicity. J Gastroenterol Hepatol 2009;24:729-735.

11. Lee SJ, Song CW, Jeen YT, et al. Prevalence of endoscopic reflux esophagitis among Koreans. J Gastroenterol Hepatol 2001;16:373376.

12. Fujimoto K, Iwakiri R, Okamoto K, et al. Characteristics of gastroesophageal reflux disease in Japan: increased prevalence in elderly women. J Gastroenterol 2003;38 (suppl 15):3-6.

13. Lee HL, Eun CS, Lee OY, et al. Association between GERD-related erosive esophagitis and obesity. J Clin Gastroenterol 2008;42: 672-675.

14. Kim N, Lee SW, Cho SI, et al. The prevalence of and risk factors for erosive oesophagitis and non-erosive reflux disease: a nationwide multicentre prospective study in Korea. Aliment Pharmacol Ther 2008;27:173-185.

15. Ronkainen J, Agréus L. Epidemiology of reflux symptoms and GORD. Best Pract Res Clin Gastroenterol 2013;27:325-337.

16. Seo GS, Jeon BJ, Chung JS, et al. The prevalence of erosive esophagitis is not significantly increased in a healthy Korean population Could it be explained?: a multi-center prospective study. J Neurogastroenterol Motil 2013;19:70-77.

17. Fass R, Shapiro M, Dekel R, Sewell J. Systematic review: proton-pump inhibitor failure in gastro-oesophageal reflux disease--where next? Aliment Pharmacol Ther 2005;22:79-94.

18. Lee ES, Kim N, Lee SH, et al. Comparison of risk factors and clinical responses to proton pump inhibitors in patients with erosive oeso- phagitis and non-erosive reflux disease. Aliment Pharmacol Ther 2009;30:154-164

19. Mohd H, Qua CS, Wong CH, Azman W, Goh KL. Non-cardiac chest pain: prevalence of reflux disease and response to acid suppression in an Asian population. J Gastroenterol Hepatol 2009;24: 288-293.

20. Chunlertrith K, Boonsawat W, Zaeoue U. Prevalence of gastroesophageal reflux symptoms in asthma patients at Srinagarind Hospital. J Med Assoc Thai 2005;88:668-671.

21. Qua CS, Wong CH, Gopala K, Goh KL. Gastro-oesophageal reflux disease in chronic laryngitis: prevalence and response to acid-suppressive therapy. Aliment Pharmacol Ther 2007;25:287-295.

22. Heading RC, Mönnikes H, Tholen A, Schmitt H. Prediction of response to PPI therapy and factors influencing treatment outcome in patients with GORD: a prospective pragmatic trial using pantoprazole. BMC Gastroenterol 2011;11:52.

23. Kim JY, Kim N, Seo PJ, et al. Association of sleep dysfunction and emotional status with gastroesophageal reflux disease in Korea. J Neurogastroenterol Motil 2013;19:344-354.

24. Kim SE, Kim N, Oh S, et al. Predictive factors of response to proton pump inhibitors in Korean patients with gastroesophageal reflux disease. J Neurogastroenterol Motil 2015;21:69-77.

25. Goh KL, Choi MG, Hsu WP, et al. Unmet treatment needs of gastroesophageal reflux disease in Asia: gastroesophageal reflux disease in Asia Pacific survey. J Gastroenterol Hepatol 2014;29:1969-1975.

26. Kim N. Past, present, and future of Journal of Neurogastroenterology and Motility. Sci Ed 2014;1:43-45. 